\title{
Longitudinal behavior of autoimmune GH deficiency: from childhood to transition age
}

\author{
Annamaria De Bellis ${ }^{1, *}$, Giuseppe Bellastella ${ }^{2, *}$, Maria Ida Maiorino ${ }^{2}$, \\ Ernesto Aitella ${ }^{3}$, Emma Lucci ${ }^{2}$, Domenico Cozzolino ${ }^{3}$, Antonio Bellastella ${ }^{1}$, \\ Antonio Bizzarro ${ }^{3}$, Dario Giugliano ${ }^{2}$ and Katherine Esposito ${ }^{3}$ on behalf of the Italian \\ Autoimmune Hypophysitis Network Group ${ }^{\dagger}$
}

\begin{abstract}
${ }^{1}$ Department of Cardiothoracic and Respiratory Sciences, Endocrinology and Metabolic Diseases Unit, Second University of Naples, Piazza L. Miraglia 2, 80131 Napoli, Italy, ${ }^{2}$ Department of Medical, Surgical, Neurological, Metabolic and Geriatric Sciences, Endocrinology and Metabolic Diseases Unit and ${ }^{3}$ Department of Clinical and Experimental Medicine, Second University of Naples, Napoli, Italy

*(A De Bellis and G Bellastella contributed equally to this work).

${ }^{\dagger}$ (Details of this group is presented in the Acknowledgements section)
\end{abstract}

Correspondence should be addressed to A De Bellis

Email

annamaria.debellis@unina2.it

\section{Abstract}

Background: Some cases of apparently idiopathic GH deficiency (GHD) may be caused by pituitary autoimmunity.

Objective: To study the variations in pituitary function and antipituitary antibodies (APA) from childhood to transition age in patients with apparently idiopathic GHD.

Design: We conducted a longitudinal study.

Patients and methods: Pituitary function and APA detection by immunofluorescence were investigated in 24 childhood patients with isolated GHD before starting recombinant GH therapy and after the stopping of this therapy in transition age. Sera of patients positive for APA were processed by double immunofluorescence to identify their pituitary target.

Results: At diagnosis, 16 out of 24 patients were APA positive targeting only somatotrophs (group 1), while the remaining eight were APA negative (group 2). When retested off therapy, 12 out of 16 patients in group 1 persisted being APA positive, while the remaining four became negative with recovery of pituitary function. All patients in group 2 persisted being APA negative but still showing GHD. Of the 12 patients persistently APA positive, eight with confirmed GHD showed APA still targeting somatotrophs, whereas four showed APA targeting only gonadotrophs associated with isolated hypogonadotropic hypogonadism $(\mathrm{HH})$.

Conclusion: Patients with APA at middle but not at high titer in childhood may show a remission of autoimmune GHD in childhood after GH replacement therapy. As APA may shift their target in transition period, an early characterization of APA by double immunofluorescence is advisable in APA positive GHD patients showing delayed puberty, to allow an early diagnosis and an appropriate therapy, thus preventing the progression toward $\mathrm{HH}$.

\section{Introduction}

For a long time, on the basis of the detection of some organ-specific antibodies, many endocrine diseases, previously considered as idiopathic, have been recognized as autoimmune $(1,2,3,4,5,6)$. In previous studies, it has been reported that antipituitary antibodies (APA) at high titers may be present in some patients with apparently idiopathic selective hypopituitarism (c) 2016 European Society of Endocrinology Printed in Great Britain suggesting an autoimmune pituitary involvement in these cases $(7,8,9)$. However, as the pituitary gland contains several different hormone-secreting cells, fourlayer double immunofluorescence may be considered an appropriate method to identify the secreting cells targeted by APA. By using this method we were able to selectively identify the type of pituitary hormone-secreting cells 
targeted by APA in adults and in children with isolated idiopathic growth hormone deficiency (GHD), in patients with idiopathic hypogonadotropic hypogonadism $(\mathrm{HH})$ and in those with isolated adrenocorticotrophic hormone (ACTH) deficiency $(10,11,12,13)$. In particular, specific staining by double immunofluorescence either of somatotrophs, gonadotrophs, or ACTH-secreting cells alone, characterized respectively isolated $\mathrm{GHD}$, isolated $\mathrm{HH}$, or isolated ACTH-deficiency.

So far, possible changes of anterior pituitary function and APA in patients with isolated autoimmune hypopituitarism without imaging alterations of hypothalamicpituitary region have been observed only in patients progressing from subclinical to clinical phase (14). Instead, the possible time-related variations of APA and of anterior pituitary function before and after replacement therapy in patients in clinical phase of isolated autoimmune hypopituitarism and in particular in those with autoimmune GHD diagnosed and treated with replacement recombinant GH (rGH) therapy since childhood, have so far never been investigated.

Prompted by these observations, this longitudinal study was aimed at investigating in patients with childhood onset autoimmune GHD, treated with $\mathrm{rGH}$, possible time-related variations in APA and anterior pituitary function from childhood to transitional age period.

\section{Patients and methods}

\section{Patients}

We enrolled for this study 24 pre-pubertal patients with childhood onset GHD (14 males and 10 females, age range at diagnosis 7-9.1 years) from 36 patients diagnosed between 2002 and 2005 at the Endocrinology and Metabolism Unit of the University Hospital of the Second University of Naples as having idiopathic GHD. The diagnosis of idiopathic isolated GHD was established on the basis of the following criteria: short stature (age and sex adjusted height $<2$ SDS, reduced growth velocity $<25$ th centile, delayed skeletal development and blunted $\mathrm{GH}$ response $<8 \mu \mathrm{g} / \mathrm{l}$ to two pharmacologic stimulation tests), as previously described (11). Magnetic resonance imaging (MRI) of the hypothalamic pituitary region and basal and dynamic secretion of other pituitary hormones were normal in all patients. All 24 patients, after the diagnosis and the basal assessment, started replacement rGH therapy, which was continued for about 8 years until the transition period (at initial dose of $0.030 \pm 10 \mathrm{mg} / \mathrm{kg}$ per day). The period of transition was arbitrarily defined as period of late adolescence when GH treatment is usually stopped for the achievement of adult stature. Twelve months after the interruption of rGH therapy, a complete reevaluation of pituitary function was performed until February 2015. Moreover, APA, already evaluated in all patients at the enrolment, were re-evaluated after rGH interruption in transition period and MRI of hypothalamic-pituitary region, already performed at diagnosis, was repeated after the stopping of therapy.

Patients and their parents gave informed written consent to participate in the study, which was approved by the Institutional Review Board.

\section{Methods}

APA evaluation - APA were detected by simple indirect immunofluorescence method on cryostat sections of young baboon pituitary gland supplied by Alifax S.r.l. (Polverara, Pordenone, Italy), as previously described (7). In particular, FITC conjugated goat antihuman Ig was used to detect the presence of APA; they were considered positive starting at dilution of 1:8. In our laboratory APA present at titer ranging from $1: 16$ to $1: 32$ are considered positive at middle titer; those positive $>1: 32$ are considered to be at high titer.

APA was also evaluated both in sera of 30 sex/agematched healthy subjects followed from childhood to transition age. Moreover, sera of APA positive patients and four control sera negative for these antibodies were retested by four layer double immunofluorescence to characterize the pituitary cells targeted by APA (11). In particular, after the first immunostaining step, using FITC conjugated goat antihuman Ig, a second immunostaining step using rabbit antisera anti-ACTH, -GH, -thyroidstimulating hormone (TSH), -prolactin (PRL), -luteinizing hormone (LH), -follicle-stimulating hormone (FSH) separately (Histo-line Srl, Milano, Italy), followed by rhodamine anti-rabbit Ig, was performed. The close correspondence between the cells colored in green in the first step and those colored in red in the second step, after the treatment with the antisera anti- each pituitary hormone, separately, followed by rhodamine anti-rabbi Ig, indicates what pituitary-secreting cells are targeted by APA.

Anterior pituitary function $>$ Basal anterior pituitary hormones (ACTH, FSH, LH, TSH, GH, and PRL) and their respective target organ hormones (cortisol, gonadal hormones, FT4, FT3, and insulin-like growth factor 1 (IGF-1)) and dynamic evaluation were performed as previously described (14). In particular, the diagnosis of 
GHD in transition phase after the stopping of GH therapy was defined by growth velocity $<2 \mathrm{~cm} /$ year, low IGF-1 levels below 2 s.D. of normal range, and a GH peak $<11 \mu \mathrm{g} / \mathrm{l}$ to GH-releasing hormone + arginine in patients with BMI ranging from 20 to $25 \mathrm{~kg} / \mathrm{m}^{2}$, GH peak $<8 \mu \mathrm{g} / 1$ in those with BMI from 25 to $30 \mathrm{~kg} / \mathrm{m}^{2}$ and GH peak $<4 \mu \mathrm{g} / \mathrm{l}$ in those with BMI $>30 \mathrm{~kg} / \mathrm{m}^{2}$ (15). The diagnosis of $\mathrm{HH}$ in the transition period was defined in patients who had not yet reached complete spontaneous puberty in association with low serum sex steroids in the setting of normal or low gonadotropin levels $(16,17)$.

\section{Statistical analysis}

Statistical analysis was performed by using the SPSS 13.0 program. Data are expressed as mean \pm s.D., unless otherwise specified. Nonparametric tests were used because of the non-Gaussian distribution of the data. The differences between the frequencies were evaluated by the Fisher exact test. The differences between the groups were compared by unpaired $t$ test, and not normally distributed two groups were compared by Mann-Whitney $U$ test. $P<0.05$ was considered statistically significant.

\section{Results}

On the basis of the presence of APA at first observation in childhood, the patients were divided into two groups: APA was present with titers ranging from 1:32 to 1:256 in 16 out of 24 patients $(66.7 \%)$, suggesting the diagnosis of autoimmune hypophysitis (group 1), while they were absent in the remaining eight patients (group 2). The basal characteristics of APA-positive and -negative patients with GHD at diagnosis are summarized in Table 1. In particular, in sera of all the patients in group 1, APA immunostained only one type of pituitary cell, identified as somatotrophs by double immunofluorescence. Moreover, the frequency of autoimmune organ-specific antibodies was significantly higher in group 1 than in group 2. In Table 2 are summarized the values of GH peak, IGF-1, height SDS, target height at diagnosis and attained height, GH peak, and IGF-1 at re-evaluation in transition period after stopping the rGH therapy. The relationship between immunological and hormonal characteristics in childhood and during the transition period in patients of group 1 is illustrated in Fig. 1. In particular, four of them (25\%) with the presence of APA to somatotrophs at middle titers (1:32) during childhood showed disappearance of APA associated with complete recovery of anterior pituitary function during the subsequent re-evaluation
Table 1 Basal characteristics of the 24 childhood patients with isolated GHD before the start of $\mathrm{rGH}$ therapy. Data are presented as $n(\%)$.

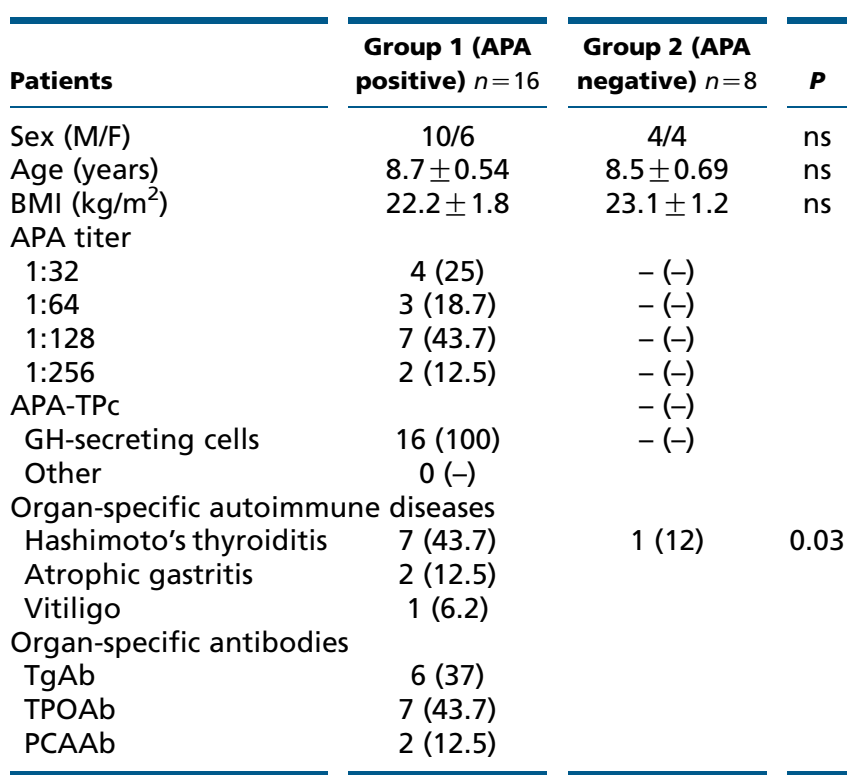

PCAAb, parietal-cell antibodies; APA-TPC, types of pituitary hormonesecreting cells targeted by APA.

in transition period after stopping rGH therapy. The other 12 of them (75\%), positive for APA directed to somatotrophs at high titer ( $>1: 32)$ at diagnosis, persisted being APA positive even at titers ranging from 1:16 to 1:32 that were significantly lower with respect to the starting titers $(P<0.001)$. As regards to the type of hormone-secreting cells immunostained by APA in the transition period, in eight of 12 patients, APA still immunostained somatotrophs selectively with persistence of isolated GHD. These eight patients showed spontaneous complete puberty and normal MRI characteristics of hypothalamic pituitary region, except for one of them showing partial empty sella. In the other four patients (all males) APA did not immunostain somatotrophs, as occurring in childhood, but did immunostain gonadotrophs only (Fig. 2). Moreover, at the same time (age range between 20.7 and 21 years) a recovery of GHD but an incomplete puberty was observed. Therefore, on the basis of testosterone, LH and FSH levels (testosterone $0.3-1 \mathrm{ng} / \mathrm{ml}$, FSH $0.4-1 \mathrm{IU} / \mathrm{l}, \mathrm{LH}$ $0.2-0.6 \mathrm{IU} / \mathrm{l}$ respectively), testis volume ranging between 4 and $6 \mathrm{ml}$, anamnestic history of delayed puberty at the age of 14-16 years, without alterations of hypothalamicpituitary region on MRI nor anosmia, the diagnosis of isolated autoimmune HH was done. Further all eight APA negative patients in group 2 persisted being APA negative in transition period but still showing isolated GHD. 
Table 2 Values of GH peak, IGF1, height SDS, target height at diagnosis and attained height, GH peak, IGF-1 at reevaluation in transition period after stopping the $\mathrm{rGH}$ therapy.

\begin{tabular}{|c|c|c|c|c|c|c|c|c|c|}
\hline \multirow[b]{2}{*}{ Patients no } & \multirow[b]{2}{*}{ Sex } & \multicolumn{5}{|c|}{ At diagnosis (age: 7-9.5 years) } & \multicolumn{3}{|c|}{ At re-evaluation (age: $18.5-21$ years) } \\
\hline & & Age & $\begin{array}{c}\text { GH peak } \\
(\mu \mathrm{g} / \mathrm{l})\end{array}$ & $\begin{array}{l}\text { IGF-1 } \\
(\mu g / l)\end{array}$ & $\begin{array}{l}\text { Height } \\
\text { (SDS) }\end{array}$ & $\begin{array}{l}\text { Target height } \\
(\mathrm{cm} \pm 8)\end{array}$ & $\begin{array}{c}\text { Attained } \\
\text { height }(\mathrm{cm})\end{array}$ & $\begin{array}{c}\text { GH peak } \\
(\mu \mathrm{g} / \mathrm{l})\end{array}$ & $\begin{array}{l}\text { IGF-1 } \\
(\mu \mathrm{g} / \mathrm{l})\end{array}$ \\
\hline \multicolumn{10}{|l|}{ Group 1} \\
\hline 1 & M & 8 & 3.07 & 37 & -2.5 & 166 & 167 & 8.1 & 44 \\
\hline 2 & $\mathrm{~F}$ & 8.8 & 4.0 & 48 & -2.5 & 159 & 160 & 7.8 & 72 \\
\hline 3 & $M$ & 9 & 1.8 & 44 & -2.5 & 177 & 169 & 9.2 & 81 \\
\hline 4 & $\mathrm{~F}$ & 9 & 2.4 & 50 & -2.4 & 164 & 162 & 7.8 & 42 \\
\hline 5 & $\mathrm{M}$ & 9.2 & 2.0 & 58 & -2.2 & 168 & 166 & 24 & 133 \\
\hline 6 & M & 8.5 & 2.5 & 43 & -2.6 & 170 & 165 & 22 & 118 \\
\hline 7 & $\mathrm{~F}$ & 9.1 & 1.7 & 50 & -2.3 & 164 & 160 & 9.2 & 78 \\
\hline 8 & $M$ & 8.9 & 2.2 & 45 & -2.6 & 172 & 165 & 7.7 & 80 \\
\hline 9 & $M$ & 7.8 & 2.2 & 48 & -2.6 & 163 & 167 & 21 & 137 \\
\hline 10 & $\mathrm{~F}$ & 8.3 & 3.0 & 50 & -2.5 & 156 & 155 & 25 & 168 \\
\hline 11 & $M$ & 9 & 4.8 & 46 & -2 & 166 & 168 & 23 & 141 \\
\hline 12 & $\mathrm{~F}$ & 8.6 & 2.2 & 48 & -2 & 157 & 155 & 26 & 124 \\
\hline 13 & $\mathrm{~F}$ & 9.5 & 1.8 & 45 & -2.6 & 164 & 158 & 8.6 & 49 \\
\hline 14 & $M$ & 8 & 2.0 & 35 & -2.1 & 168 & 170 & 6.0 & 74 \\
\hline 15 & $\mathrm{M}$ & 9 & 2.2 & 42 & -2.3 & 166 & 169 & 23 & 135 \\
\hline 16 & $\mathrm{M}$ & 8.9 & 3.7 & 44 & -2.2 & 164 & 164 & 22 & 112 \\
\hline \multicolumn{10}{|l|}{ Group 2} \\
\hline 17 & $M$ & 8.7 & 4.1 & 50 & -2.5 & 171 & 165 & 8.8 & 61 \\
\hline 18 & $\mathrm{~F}$ & 8.4 & 3.9 & 33 & -2 & 162 & 165 & 9.1 & 57 \\
\hline 19 & $M$ & 7 & 2.2 & 42 & -2.6 & 169 & 164 & 7.9 & 31 \\
\hline 20 & $\mathrm{~F}$ & 9 & 1.8 & 47 & -2.4 & 155 & 150 & 7.7 & 64 \\
\hline 21 & $\mathrm{~F}$ & 9.2 & 4.2 & 40 & -2.2 & 160 & 166 & 8.3 & 48 \\
\hline 22 & $M$ & 8.8 & 3.8 & 40 & -2.2 & 162 & 165 & 9.3 & 59 \\
\hline 23 & $\mathrm{~F}$ & 9.3 & 4.2 & 52 & -2.3 & 160 & 158 & 9.7 & 93 \\
\hline 24 & $M$ & 7.9 & 4.5 & 38 & -2.2 & 161 & 164 & 8.6 & 68 \\
\hline
\end{tabular}

Finally, in all normal controls APA were persistently negative at the start and end of the study.

Summarizing, autoimmune GHD, diagnosed and treated since childhood age, recovered in transition period in four patients in group 1 positive for APA at middle titer at diagnosis, with the disappearance of these antibodies, while persisted in eight out of the remaining 12 patients in this group, found positive for APA at high titer at diagnosis. Instead, the last four patients in this group showed, in transition period, a shift of pituitary target of APA from somatotrophs to gonadotrophs accompanied by recovery of GHD and onset of HH. Moreover, GHD persisted in all negative patients in group 2 with a significant higher frequency of GHD in these patients with respect to those in group $1(P=0.02)$.

\section{Discussion}

This longitudinal study describes for the first time, in APA positive patients with childhood onset isolated autoimmune GHD treated with rGH replacement therapy, a recovery of pituitary function with the disappearance of
APA in $25 \%$ of them and a shift of APA target (from somatotrophs to gonadotrophs) and of the kind of anterior pituitary dysfunction (from GHD to $\mathrm{HH}$ ) in other $25 \%$ of them in transition age, when GH treatment had been stopped.

The first point emerging from our results was the finding of the disappearance of APA with normalization of total anterior pituitary function, when retested at transition period, in four out of 16 patients (25\%) with childhood onset autoimmune GHD and presence of APA at middle titer immunostaining selectively the somatotrophs at the first observation.

It is already well demonstrated that a possible spontaneous remission during the natural history of autoimmune hypophysitis can be observed and that the recovery of pituitary function occurring after surgical or medical treatment could be related in some cases to spontaneous resolution rather than to the treatment itself $(18,19)$. Thus, a spontaneous remission of pituitary dysfunction in some of our APA positive patients cannot be excluded. However, we can hypothesize that, when APA targeting the somatotrophs are present at middle titer 


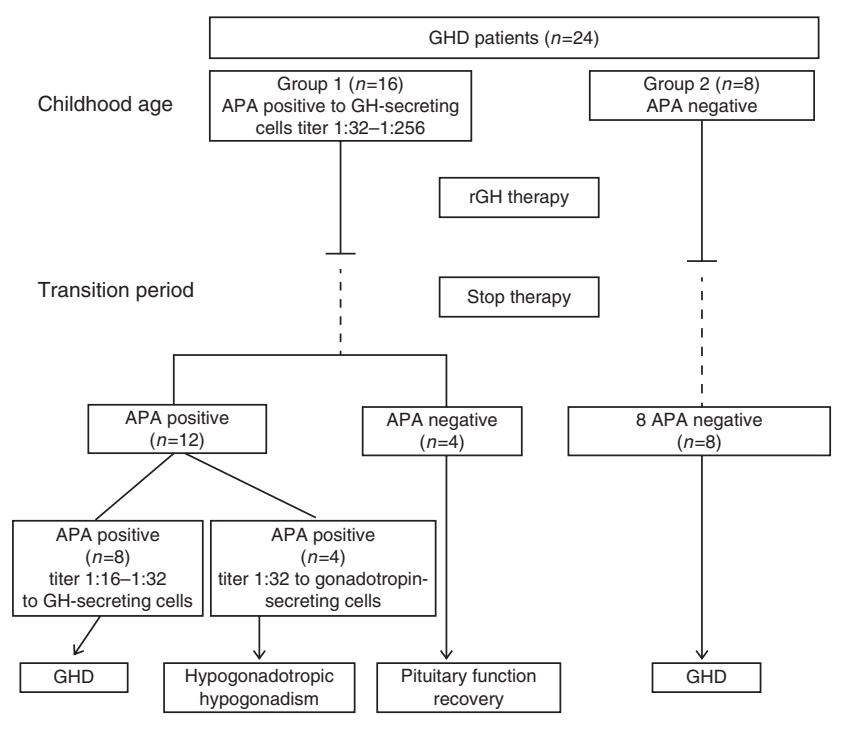

Figure 1
Behavior of APA and anterior pituitary function in transition period, 1 year after stopping the $\mathrm{rGH}$ replacement therapy in 24 patients with childhood isolated GHD.

in patients with isolated autoimmune GHD at childhood age, a possible recovery of GH secretion with disappearance of APA can subsequently occur in transition period, if the GH-secreting cells were not irreversibly damaged by the autoimmune process. A similar condition has been reported for some other autoimmune endocrine diseases, in which a remission of the autoimmune process with recovery of function of the involved hormone-secreting cells was observed, likely because these cells were previously not irreversibly damaged $(20,21)$. Instead, the persisting detection of APA accompanied by impairment of pituitary function in the other 12 patients $(75 \%)$, in whom APA to somatotrophs had been detected at high titer at diagnosis, seems to indicate that a remission of pituitary autoimmunity in transition period may not occur when the pituitary immune process was very active in childhood age. Thus, our results on the other hand confirm the usefulness of searching for APA in patients with GHD in order to disclose those with pituitary autoimmunity, as also demonstrated by other authors $(8,9,18,19,22,23)$, on the other hand seem to indicate that the titer level of these antibodies at diagnosis may help to foresee the possible future evolution of the pituitary autoimmune process.

Another interesting point emerging from our results concerns the relationship evidenced at the observation in transition period between the detection of the type of pituitary hormone-secreting cells immunostained by APA and the kind of pituitary hormone deficiency in the 12 patients with persistence of pituitary autoimmunity in this period. Among these patients, eight showed persistence of APA immunostaining solely somatotrophs, associated with persisting isolated GHD, while in the other four, pituitary target of APA shifted selectively from somatotrophs to gonadotrophs with the disappearance of GHD and the onset of $\mathrm{HH}$.

This is the first evidence in patients with autoimmune GHD, diagnosed in childhood and treated with rGH replacement therapy until the transition age, of a shift of APA from a pituitary target at diagnosis (somatotrophs) to another pituitary target (gonadotrophs) at the observation in transition period, with consequent variation of the selective kind of hypopituitarism, from GHD to $\mathrm{HH}$.

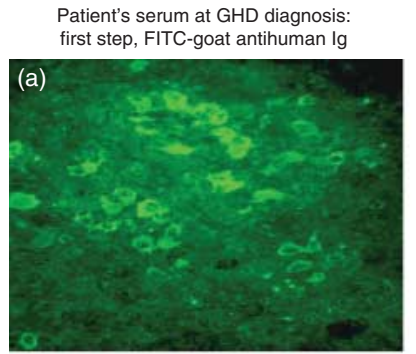

Patient's serum at revaluation: first step, FITC-goat antihuman Ig

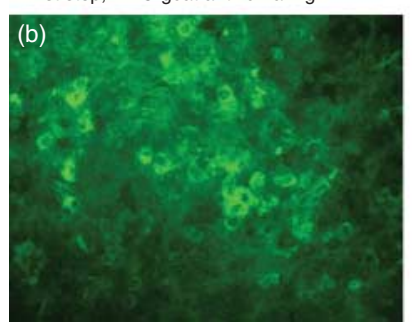

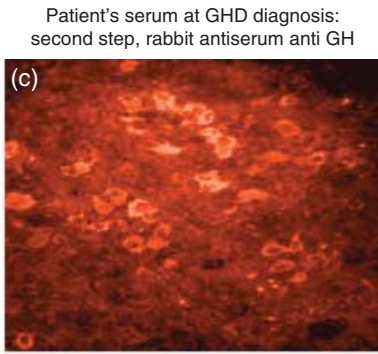

Patient's serum at revaluation: second step, rabbit antiserum anti $\mathrm{FSH} / \mathrm{LH}$

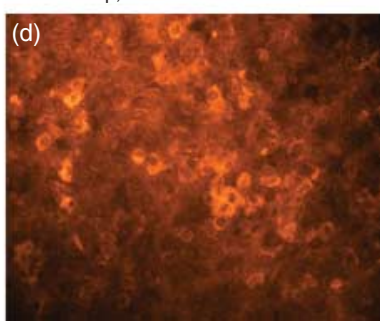

Figure 2

Detection of APA by immunofluorescence and characterization of the target of these antibodies by double immunofluorescence in one out of the four patients with GH deficiency at the diagnosis and $\mathrm{HH}$ in transition age: cryostat section of young baboon anterior pituitary gland was tested against patient's serum, adding in a primary step FITC-goat antihuman Ig ( $\mathrm{A}$ and B) and in a second step rabbit antisera anti-GH and -FSH, or - $\mathrm{LH}$ ( $C$ and $D$ ) respectively followed by rhodamine-goat sera antirabbit Ig. The close correspondence between the cells colored in green ( $A$ and $B$ ) and those colored in red ( $C$ and $D$ ) indicates that the pituitary cells targeted by APA are respectively, GH-secreting cells at diagnosis ( $A$ and $C$ ) and gonadotropin-secreting cells in transition period ( $B$ and $D)$. 
The cause of this surprising behavior is at present unknown, perhaps because the true pituitary antigen(s) responsible for the autoimmune response have yet to be identified, despite several factors being suggested as possible autoantigens $(22,23,24,25,26,27,28)$.

The results of the present study with the shift of APA target from somatotrophs to gonadotrophs, accompanied by remission of GHD and onset of $\mathrm{HH}$, seem in part to contradict our previous study in autoimmune endocrine patients positive for APA but with pituitary function still normal (29), in which we concluded that, when APA selectively immunostained only one type of pituitarysecreting cell, we were able to foresee the kind of subsequent isolated hypopituitarism. Our present results seem instead to indicate that a possible shift of the pituitary target of APA with variation of the kind of hypopituitarism may occur, especially when pituitary autoimmunity started in childhood. At present we are unable to explain why this may occur. Further studies aimed at ascertaining the true pituitary antigens evoking the autoimmune response and investigating whether any endogenous and/or environmental factor may increase or decrease some of these antigens from childhood to adult age, could contribute to clarify this aspect.

Instead, the majority of patients in group 1 persistently showed isolated GHD at the observation in transition period, likely because the presence of APA positive at high titer at diagnosis testified the occurrence in childhood of a very aggressive immune process, damaging severely the $\mathrm{GH}$-secreting cells, thus not allowing a functional recovery of their function.

In conclusion, our results indicate that patients with autoimmune GHD, diagnosed and treated with $\mathrm{rGH}$ replacement therapy since childhood, may show in transition age, after stopping the treatment, three different conditions, particularly depending on the titer of APA at diagnosis and the possible variation of the pituitary target of these antibodies from the childhood to the transition age: i) the majority of them, especially if with APA at high titer at diagnosis, may show a persisting GHD associated with persisting detection of APA; ii) some of them, with APA at middle titer at diagnosis, may show a recovery of pituitary function with disappearance of these antibodies, likely favored by prolonged GH replacement therapy; iii) the remaining patients, even if the autoimmune process in childhood involved only GH-secreting cells causing isolated GHD, may subsequently show a shift of APA target from somatotrophs to gonadotrophs, with remission of GHD and onset of autoimmune $\mathrm{HH}$.
A complete re-evaluation in transition period of pituitary function and of APA by double immunofluorescence in patients with GHD, found APA positive in childhood and treated with replacement therapy, may help to evidence the persistence or the remission of the pituitary autoimmunity, thus allowing the consequent therapeutic option. Moreover, we suggest that in future studies this re-evaluation should be made early in occurrence of delayed puberty in some patients, to allow an early diagnosis and an appropriate therapy in case of autoimmune cross-over from somatotrophs to gonadotrophs, thus preventing the progression to future $\mathrm{HH}$.

\section{Declaration of interest}

The authors declare that there is no conflict of interest that could be perceived as prejudicing the impartiality of the research reported.

\section{Funding}

This work was supported in part by grants from University Research Grants 2013, Second University of Naples.

\section{Acknowledgements}

In addition to the authors, the following members of the Italian Autoimmune Hypophysitis Network Study contributed to the collection of data and blood samples from patients with autoimmune pituitary diseases to further optimize the immunofluorescence technique: E Arvat (Turin), P Beck-Peccoz (Milan), C Betterle (Padova), A Colao (Naples), S Cannavò (Messina), L Chiovato (Pavia), M Delvecchio (S Giovanni Rotondo), R Giordano (Turin), E Ghigo (Turin), F Mantero (Padova), L Persani (Milan), M Rotondi (Pavia), M Salerno (Naples), A Spada (Milan), and MC Zatelli (Ferrara).

\section{References}

1 Bottazzo GF, Florin-Christensen A \& Doniach D. Islet-cell antibodies in diabetes mellitus with autoimmune polyendocrine deficiencies. Lancet 197430 1279-1283. (doi:10.1016/S0140-6736(74)90140-8)

2 Bottazzo GF \& Doniach D. Autoimmune thyroid disease. Annual Review of Medicine 198637 353-359. (doi:10.1146/annurev.me.37.020186. 002033)

3 Falorni A, Laureti S, De Bellis A, Zanchetta R, Tiberti C, Arnaldi G, Bini V, Beck-Peccoz P, Bizzarro A, Dotta F et al. Italian Addison network study: update of diagnostic criteria for the etiological classification of primary adrenal insufficiency. Journal of Clinical Endocrinology and Metabolism 200489 1598-1604. (doi:10.1210/jc.2003-030954)

4 Falorni A, Laureti S, Candeloro P, Perrino S, Coronella C, Bizzarro A, Bellastella A, Santeusanio F \& De Bellis A. Steroid-cell autoantibodies are preferentially expressed in women with premature ovarian failure who have adrenal autoimmunity. Fertility and Sterility 200278 270-279. (doi:10.1016/S0015-0282(02)03205-3)

5 Brozzetti A, Alimohammadi M, Morelli S, Minarelli V, Hallgren A, Giordano R, De Bellis A, Perniola R, Kämpe O, Falorni A et al. Autoantibody response against NALP5/MATER in primary ovarian insufficiency and in autoimmune Addison's disease. Journal of Clinical 
Endocrinology and Metabolism 2015100 1941-1948. (doi:10.1210/jc. 2014-3571)

6 De Bellis A, Colao A, Bizzarro A, Di Salle F, Coronella C, Solimeno S, Vetrano A, Pivonello R, Pisano G, Lombardi G et al. Longitudinal study of vasopressin-cell antibodies and of hypothalamic-pituitary region on magnetic resonance imaging in patients with autoimmune and idiopathic complete central diabetes insipidus. Journal of Clinical Endocrinology and Metabolism 200287 3825-3829. (doi:10.1210/jcem. 87.8.8757)

7 De Bellis A, Bizzarro A, Conte M, Perrino S, Coronella C, Solimeno S, Sinisi AM, Stile LA, Pisano G \& Bellastella A. Antipituitary antibodies in adults with apparently idiopathic growth hormone deficiency and in adults with autoimmune endocrine diseases. Journal of Clinical Endocrinology and Metabolism 200388 650-654. (doi:10.1210/jc.2002021054)

8 Bensing S, Kasperlik-Zaluska AA, Czarnocka B, Crock PA \& Hulting A. Autoantibodies against pituitary proteins in patients with adrenocorticotropin-deficiency. European Journal of Clinical Investigation 2005 35 126-132. (doi:10.1111/j.1365-2362.2005.01459.x)

9 Manetti L, Lupi I, Morselli LL, Albertini S, Cosottini M, Grasso L, Genovesi M, Pinna G, Mariotti S, Bogazzi F et al. Prevalence and functional significance of antipituitary antibodies in patients with autoimmune and non-autoimmune thyroid diseases. Journal of Clinical Endocrinology and Metabolism 200792 2176-2181. (doi:10.1210/jc. 2006-2748)

10 De Bellis A, Bizzarro A, Perrino S, Coronella C, Conte M, Pasquali D, Sinisi AA, Betterle C \& Bellastella A. Characterization of antipituitary antibodies targeting pituitary hormone-secreting cells in idiopathic growth hormone deficiency and autoimmune endocrine diseases. Clinical Endocrinology 200563 45-49. (doi:10.1111/j.1365-2265.2005. 02296.x)

11 De Bellis A, Salerno M, Conte M, Coronella C, Tirelli G, Battaglia M, Esposito V, Ruocco G, Bellastella G, Bizzarro A et al. Antipituitary antibodies recognizing growth hormone (GH)-producing cells in children with idiopathic GH deficiency and in children with idiopathic short stature. Journal of Clinical Endocrinology and Metabolism 200691 2484-2489. (doi:10.1210/jc.2006-0040)

12 De Bellis A, Sinisi AA, Conte M, Coronella C, Bellastella G, Esposito D, Pasquali D, Ruocco G, Bizzarro A \& Bellastella A. Antipituitary antibodies against gonadotropin-secreting cells in adult male patients with apparently idiopathic hypogonadotropic hypogonadism. Journal of Clinical Endocrinology and Metabolism 200792 604-607. (doi:10.1210/jc.2006-1216)

13 De Bellis A, Pane E, Bellastella G, Sinisi AA, Colella C, Giordano R, Giavoli C, Lania A, Ambrosio MR, Di Somma C et al. Detection of antipituitary and antihypothalamus antibodies to investigate the role of pituitary or hypothalamic autoimmunity in patients with selective idiopathic hypopituitarism. Clinical Endocrinology 201175 361-366. (doi:10.1111/j.1365-2265.2011.04056.x)

14 Bellastella G, Rotondi M, Pane E, Dello Iacovo A, Pirali B, Dalla Mora L, Falorni A, Sinisi AA, Bizzarro A, Colao A et al. Predictive role of the immunostaining pattern of immunofluorescence and the titers of antipituitary antibodies at presentation for the occurrence of autoimmune hypopituitarism in patients with autoimmune polyendocrine syndromes over a five-year follow-up. Journal of Clinical Endocrinology and Metabolism 201095 3750-3757. (doi:10.1210/jc.2010-0551)
15 Cook DM \& Rose SR. A review of guidelines for use of growth hormone in pediatric and transition patients. Pituitary 201215 301-310. (doi:10. 1007/s11102-011-0372-6)

16 Dwyer AA, Phan-Hug F, Hauschild M, Elowe-Gruau E \& Pitteloud N. Transition in endocrinology: Hypogonadism in adolescence. European Journal of Endocrinology 2015173 R15-R24. (doi:10.1530/EJE-14-0947)

17 Sinisi AA, Esposito D, Bellastella G, Maione L, Palumbo V, Gandini L, Lombardo F, De Bellis A, Lenzi A \& Bellastella A. Efficacy of recombinant human follicle stimulating hormone at low doses in inducing spermatogenesis and fertility in hypogonadotropic hypogonadism. Journal of Endocrinological Investigation 201033 618-623. (doi:10.1007/BF03346659)

18 Caturegli P, Newschaffer C, Olivi A, Pomper MG, Burger PC \& Rose NR. Autoimmune hypophysitis. Endocrine Reviews 200526 599-614. (doi:10.1210/er.2004-0011)

19 Beressi N, Beressi JP, Cohen R \& Modigliani E. Lymphocytic hypophysitis. A review of 145 cases. Annals of Internal Medicine 1999150 327-341.

20 De Bellis A, Bizzarro A, Rossi R, Paglionico VA, Criscuolo T, Lombardi G $\&$ Bellastella A. Remission of subclinical adrenocortical failure in subjects with adrenal autoantibodies. Journal of Clinical Endocrinology and Metabolism 199376 1002-1007. (doi:10.1210/jcem.76.4.8473373)

21 Eisenbarth GS \&Verge CF. Immunoendocrinopathy syndromes. In Williams Textbook of Endocrinology, 9th edn, pp 1651-1662. Eds JD Wilson, DW Foster, HM Kronenberg \& PR Larsen. Philadelphia: Saunders Elsevier, 1998.

22 Caturegli P, Lupi I, Landek-Salgado M, Kimura H \& Rose NR. Pituitary autoimmunity: 30 years later. Autoimmunity Reviews 20087 631-637. (doi:10.1016/j.autrev.2008.04.016)

23 Takao T, Nanamiya W, Matsumoto R, Asaba K, Okabayashi T \& Hashimoto K. Antipituitary antibodies in patients with lymphocytic hypophysitis. Hormone Research 200155 288-292. (doi:10.1159/ 000050015)

24 Crock PA. Cytosolic autoantigens in lymphocytic hypophysitis. Journal of Clinical Endocrinology and Metabolism 199883 609-618. (doi:10.1210/jcem.83.2.4563)

25 O'Dwyer DT, Smith AI, Matthew ML, Andronicos NM, Ranson M, Robinson PJ \& Crock PA. Identification of the 49-kDa autoantigen associated with lymphocytic hypophysitis as alpha-enolase. Journal of Clinical Endocrinology and Metabolism 200287 752-757. (doi:10.1210/jc.87.2.752)

26 Tanaka S, Tatsumi KI, Kimura M, Takano T, Murakami Y, Takao T, Hashimoto K, Kato Y \& Amino N. Detection of autoantibodies against the pituitary-specific proteins in patients with lymphocytic hypophysitis. European Journal of Endocrinology 2002147 767-775. (doi:10.1530/ eje.0.1470767)

27 Bensing S, Fetissov SO, Mulder J, Perheentupa J, Gustafsson J, Husebye ES, Oscarson M, Ekwall O, Crock PA, Hökfelt T et al. Pituitary autoantibodies in autoimmune polyendocrine syndrome type 1. PNAS 2007104 949-954. (doi:10.1073/pnas.0610070104)

28 Lupi I, Broman KW, Tzou SC, Gutenberg A, Martino E \& Caturegli P. Novel autoantigens in autoimmune hypophysitis. Clinical Endocrinology 200869 269-278. (doi:10.1111/j.1365-2265.2008.03180.x)

29 De Bellis A, Dello Iacovo A, Bellastella G, Savoia A, Cozzolino D, Sinisi AA, Bizzarro A, Bellastella A \& Giugliano D. Characterization of pituitary cells targeted by antipituitary antibodies in patients with isolated autoimmune diseases without pituitary insufficiency may help to foresee the kind of future hypopituitarism. Pituitary 201417 457-463. (doi:10.1007/s11102-013-0526-9)

Received 29 July 2015

Revised version received 8 October 2015

Accepted 23 November 2015 